\title{
Estimation of meat amount by non-linear multiple regression equations using in vivo and carcass measurements on Teleorman Black Head lambs
}

\author{
C. Lazar ${ }^{1,3}$, M.Al. Gras ${ }^{1}$, R.S. Pelmus ${ }^{1}$, C.M. Rotar ${ }^{1}$, E. Ghita ${ }^{1}$ and R. Burlacu² \\ ${ }^{1}$ National Research Development Institute for Animal Biology and Nutrition (INCDBNA), Laboratory of Animal Biology \\ Calea Bucuresti no. 1, Balotesti, Ilfov, 077015, Romania \\ ${ }^{2}$ University of Agronomic Sciences and Veterinary Medicine of Bucharest \\ 59 Mărăşti Boulevard, District 1, 011464 Bucharest, Romania
}

KEY WORDS: carcass, commercial cuts, non-linear multiple regression equations, ultrasound measurements, lamb, local breed

Received: $\quad 18$ May 2015

Revised: $\quad 10$ August 2016

Accepted: 10 December 2016

${ }^{3}$ Corresponding author:

e-mail: cristina_lazar17@yahoo.com

\begin{abstract}
In the present study non-linear multiple regression equations and carcass ultrasound measurements were used to estimate the amount of meat in carcass and commercial cuts in local breed Teleorman Black Head (TBH). The measurements were conducted on 79 TBH lambs aged 2.5 months, in two points (P1 - located $5 \mathrm{~cm}$ from the spine, in line with the $12^{\text {th }}$ rib; P2 - located between $3^{\text {rd }}$ and $4^{\text {th }}$ lumbar) of longisimus dorsi muscle to obtain the following parameters: subcutaneous fat layer thickness $(2.21 ; 2.03 \mathrm{~mm})$, muscle depth $(20.81 ; 19.54 \mathrm{~mm})$, muscle eye area $\left(8.93 ; 8.71 \mathrm{~cm}^{2}\right)$ and muscle perimeter (121.97; $121.57 \mathrm{~mm})$. The non-linear multiple regression equations based on all four ultrasound parameters measured in $\mathrm{P} 1$ gave the most precise estimations for carcass meat and commercial cuts: leg and loin (0.994), shoulder (0.963) and rack (0.938). The best estimations of the carcass meat amount and half carcass meat amount using three ultrasound parameters (depth, eye area and perimeter of muscle) were obtained in $\mathrm{P} 1$, with a precision of 0.818 and 0.803 , respectively. Non-linear multiple regression equations using only one ultrasound parameter (muscle eye area) measured in P2 gave the most precise estimations for: carcass meat $(0.916)$, half carcass meat $(0.880)$ and commercial cuts such as loin (0.976), rack (0.950) and shoulder (0.911). The non-linear multiple regression equations developed by using ultrasounds parameters showed very high precision coefficients, which suggests that only ultrasound measurements and proposed equations might be used to estimate the meat production and to improve the evaluation of sheep selected for meat production.
\end{abstract}

\section{Introduction}

The European and worldwide trend for sheep breeding and selection is mainly directed towards increasing the meat production and quality. Many studies conducted with the purpose to improve the quality and production of sheep meat evaluated the influence of various parameters: age (starting with the weaning age, when the lamb reaches a live weight of about $20-25 \mathrm{~kg}$ ), breed, weight, sex, carcass traits and meat production type. For instance, AbdelMoneim (2009) compared three intensively reared Egyptian breeds (Ossimi, Barki and Rahmani) and noticed that the live weight $(26.1,25.8,24.3 \mathrm{~kg}$, 
respectively) and the breed of lambs did not have a large influence on the dimension of longisimus dorsi (LD) muscle eye area. However, the best carcass traits for the fat content in carcass were determined in Barki lambs. For lamb meat the market imposed new quality standards for the evaluation of sheep carcasses using the EUROP system (E - excellent, $\mathrm{U}$ - very good, $\mathrm{R}$ - good, $\mathrm{O}$ - fair and $\mathrm{P}$ poor), which meets the food quality and safety requirements of the European consumers and enables the objective evaluation of the carcass meat and payment in agreement with its quality. The classical method of carcass grading required measurements after animals slaughtering. Several grading methods have been developed in time for the determination of carcass composition and quality in lambs (Ibrahim et al., 2007). Carcass cutting and measurement, as well as the physicochemical analyses are the methods most often used for investigation. These measurements are time consuming and expensive (transport to the slaughterhouse, slaughtering, etc.), and their biggest disadvantage is that the selected animals could no longer be used for reproduction. Hence, the trend was to remove these inconveniencies by improving the carcass grading techniques (Dewi et al., 2002). The ultrasound measurement is a new technique which is a non-invasive, efficient grading method for classification and quantification of the animal carcasses in their early life as well as the further usage of animals for reproduction. The measured parameters (subcutaneous fat layer thickness, muscle eye area and muscle depth) add new selection indices (muscle depth and subcutaneous fat layer thickness) to the classical ones (body weight, carcass meat). The ultrasound method is mostly used for sheep carcass grading in the western EU countries which have a long tradition in sheep rearing and breeding for meat production. Applications of this modern technology are already deployed in the UK, New Zealand and Ireland for the breeding programmes (Fogarty et al., 1992, 1995; Wilson, 1992; Russel, 1995; Larsgard and Kolstad, 2003), showing very good correlations with the classical method. The in vivo evaluation of sheep carcass was done by real-time ultrasound measurement (RT ultrasound) and by image analysis at two frequencies (5 MHz and 7.5 MHz; Silva et al., 2006). The last method have also been used for other species (e.g., pigs) for a more efficient evaluation of the meat carcass, and no differences were found between the ultrasound technique (in vivo) and carcass measurements, and slot two techniques (Hebean et al., 2009; Hăbeanu et al., 2010). This ultrasound technology has also been applied by Houghton and Turlington
(1992) in the feeding programmes for steers in order to estimate the body weight in correlation with carcass composition. The inclusion of ultrasound measurement values into multiple regression equations together with the body weight value improved the estimation of the muscle tissue weight and the evaluation of carcass fat content. Fernández et al. (1997) stated close correlations between the ultrasound measurements and the carcass measurements of LD muscle for muscle eye area, muscle depth and thickness of the subcutaneous fat layer $(0.88,0.74$ and 0.56 , respectively) in Manchego lambs. Moderate correlations between the ultrasound measurements and the carcass assessment for muscle eye area and weaning body weight, and between the thickness of the subcutaneous fat layer and weaning body weight were determined by Fernández et al. (1998) and Ibrahim et al. (2007). Close phenotypic correlations were observed between the ultrasound measurements and the carcass measurements in steers by Devitt and Wilton (2001), who also estimated the genetic progress for the carcass traits. Silva et al. (2006) and Cadavez and Monteiro (2011) used multiple regression equations to predict the composition of Chura, Galega, Bragancana and Suffolk lamb carcasses, using the weight of the warm carcass and the ultrasound parameters (the proportion of subcutaneous fat, the intramuscular fat content, the thickness of subcutaneous fat layer and the bone weight) in order to obtain an objective classification and grading of sheep carcasses. Emenheiser et al. (2010) showed the necessity of validating the ultrasound method utilization to determine lamb carcass composition for meat production and showed the advantages of this method. In order to improve the evaluation of the sheep selected for meat production, the purpose of this study was to develop non-linear multiple regression equations to evaluate the amount of carcass meat and the amount of selected cuts in local breed Teleorman Black Head lambs by using carcass and ultrasound measurements of the subcutaneous fat layer thickness, muscle depth, muscle eye area and perimeter of the muscle area of LD muscle.

\section{Material and methods}

\section{Animals}

The study was conducted on 79 Teleorman Black Head (TBH) lambs aged 2.5 months, in a farm in Teleorman County (Romania). Body weight at birth (BWB) and body weight at 2.5 months (BWM2.5) were measured in order to determine the average body weight gain (ABWG). 


\section{Ultrasound measurements}

The ultrasound measurements have been performed on all $79 \mathrm{TBH}$ lambs with an Echo Blaster 64 with LV 7.5 65/64 probe (TELEMED Ultrasound Medical Systems, Milano, Italy). All ultrasound images were recorded and analysed with Echo Wave II 1.32 software (TELEMED Ultrasound Medical Systems, Milano, Italy). The first measuring point (P1) was located $5 \mathrm{~cm}$ from the spine, in line with the $12^{\text {th }}$ rib; the second measuring point $(\mathrm{P} 2)$ was located between $3^{\text {rd }}$ and $4^{\text {th }}$ lumbar vertebrae. A large proportion of longisimus dorsi (LD) muscle is situated between these two measuring locations and this provides information on the parameters which are important for the evaluation of meat production in lambs: subcutaneous fat layer thickness (F12, F34), muscle depth (M12, M34), muscle eye area (A12, A34) and muscle perimeter (P12, P34) at $12^{\text {th }}$ rib and between $3^{\text {rd }}$ and $4^{\text {th }}$ lumbar vertebrae area of LD muscle, respectively.

\section{Carcass measurements}

After slaughtering the carcass measurements were carried out only on 12 lambs. Carcasses carving was done by French method described by Flamant and Boccard (1966) that results in five commercial cuts: leg loin, rack, shoulder, flank and neck. The commercial cuts were weighted in whole and with the distribution into meat and bones, and the following calculation were made: commercial yield, slaughterhouse yield, meat : bone ratio, bone percentage.

\section{Correlations}

Correlations were calculated between the traits obtained using ultrasound method (subcutaneous fat layer thickness, muscle depth, muscle eye area, muscle perimeter) and the classical body measurements (weight at birth and at 2.5 months, total weight gain and average daily weight gain).

\section{Non-linear multiple regression equations}

Equations for estimating carcass meat (subcutaneous fat layer thickness, muscle depth, muscle eye area, muscle perimeter of LD muscle, and commercial cuts meat quantity) were established using ultrasound parameters. Quattro pro X5 software programme (Corel Corporation, Ottawa, ON, USA) was used for data calculation to fit the appropriate model and to determine the prediction regression functions. Non-linear multiple regression equations with four variables are as follows:

$$
\begin{gathered}
\mathrm{Y}=\mathrm{a}_{1} \mathrm{x}_{1}+\mathrm{a}_{2} \mathrm{x}_{2}+\mathrm{a}_{3} \mathrm{x}_{3}+\mathrm{a}_{4} \mathrm{x}_{4}+\mathrm{a}_{5} \mathrm{x}_{1}{ }^{2}+\mathrm{a}_{6} \mathrm{x}_{2}{ }^{2}+\mathrm{a}_{7} \mathrm{x}_{3}^{2} \\
+\mathrm{a}_{8} \mathrm{x}_{4}^{2}+\mathrm{b}
\end{gathered}
$$

where: $\mathrm{Y}$ - meat amount in carcass, leg, loin, rack, shoulder, flank, neck; $\mathrm{a}_{1}, \mathrm{a}_{1}, \mathrm{a}_{2}, \mathrm{a}_{3}, \mathrm{a}_{4}, \mathrm{a}_{5}, \mathrm{a}_{6}, \mathrm{a}_{7}, \mathrm{a}_{8}-$ regression coefficients; $b$ - intercept; $x_{1}, x_{2}, x_{3}, x_{4}-$ subcutaneous fat layer thickness, muscle depth, muscle eye area and LD muscle perimeter, respectively.

Non-linear multiple regression equations were also established to estimate carcass and half carcass meat quantity, using three ultrasound parameters (muscle depth, muscle eye area and LD muscle perimeter):

$$
\mathrm{Y}=\mathrm{a}_{1} \mathrm{X}_{1}+\mathrm{a}_{2} \mathrm{x}_{2}+\mathrm{a}_{3} \mathrm{x}_{3}+\mathrm{a}_{4} \mathrm{X}_{1}^{2}+\mathrm{a}_{5} \mathrm{x}_{2}^{2}+\mathrm{a}_{6} \mathrm{x}_{3}^{2}+\mathrm{b}
$$

where: $\mathrm{Y}$ - meat amount in half carcass and carcass; $a_{1}, a_{2}, a_{3}, a_{4}, a_{5}, a_{6}$ - regression coefficients; $b$ - intercept; $x_{1}, x_{2}, x_{3}-$ muscle depth, muscle eye area and LD muscle perimeter, respectively.

\section{Results and discussion}

Body weight evolution. In this study two methods (ultrasound and carcass measurements) were used to improve the evaluation of TBH lamb carcasses and to develop a model with non-linear multiple regression equations to estimate the amount of carcass meat. Lambs body weight at birth was $5.1 \mathrm{~kg}$, reaching $22.84 \mathrm{~kg}$ at the age of 2.5 months. The average daily body weight gain was $0.24 \mathrm{~kg}$. The average slaughter age was 73.58 days (Table 1).

Table 1. Body weight and average daily gain of Teleorman Black Head lambs

\begin{tabular}{lrrc}
\hline Indices & Mean & SEM & $\begin{array}{l}\text { Variability } \\
\text { coefficient, } \\
\%\end{array}$ \\
\hline Body weight at birth, $\mathrm{kg}$ & 5.10 & 0.14 & 9.75 \\
Body weight at 2.5 month, kg & 22.84 & 0.87 & 13.12 \\
Total gain, kg & 17.74 & 0.95 & 18.54 \\
Average daily gain, kg & 0.24 & 0.01 & 7.94 \\
Age, days & 73.58 & 4.36 & 20.54 \\
\hline
\end{tabular}

The observed body weight at birth and weaning was within the normal limits for TBH breed (Lazar et al., 2009; Ghita et al., 2010), 10.88\% higher than the body weight at birth reported by Dewi et al. (2002) for Welsh Mountain lambs. The TBH lambs were slaughtered 12 and 6 days earlier than reported by Dewi et al. (2002) for Welsh Mountain lambs and by Peña et al. (2005) for Segurena lambs, respectively.

Ultrasound measurements. The results of ultra-sound measurements on TBH lambs were within the limits of the requirements for lamb meat standard (2-2.5 months of age) (Table 2). The ultrasound 
Table 2. Ultrasound measurements of Teleorman Black Head lambs

\begin{tabular}{|c|c|c|c|c|}
\hline Indices & Mean & SEM & Variability coefficient, $\%$ & $P$-value \\
\hline \multicolumn{5}{|l|}{ Subcutaneous fat layer thickness } \\
\hline in $\mathrm{P}^{1}{ }^{1}$ (FP1), mm & 2.22 & 0.20 & 31.83 & NS \\
\hline in $P 2^{2}$ (FP2), mm & 2.03 & 0.09 & 15.88 & \\
\hline Muscle depth in P1 (MP1), mm & 20.81 & 0.62 & 10.33 & NS \\
\hline Muscle depth in P2 (MP2), mm & 19.54 & 0.56 & 9.88 & \\
\hline Muscle eye area in P1 (AP1), $\mathrm{cm}^{2}$ & 8.93 & 0.40 & 15.61 & NS \\
\hline Muscle eye area in P2 (AP2), $\mathrm{cm}^{2}$ & 8.71 & 0.24 & 9.51 & \\
\hline Muscle perimeter in P1 (PP1), mm & 121.97 & 1.78 & 5.04 & NS \\
\hline Muscle perimeter in P2 (PP2), mm & 121.57 & 1.81 & 5.15 & \\
\hline
\end{tabular}

${ }^{1} \mathrm{P} 1$ - point 1 located $5 \mathrm{~cm}$ from the spine, in line with the $12^{\text {th }}$ rib; ${ }^{2} \mathrm{P} 2$ - point 2 located between $3^{\text {rd }}$ and $4^{\text {th }}$ lumbar; NS $=P>0.05$

method was used to measure the subcutaneous fat layer thickness $(2.21$ and $2.03 \mathrm{~mm}$ in $\mathrm{P} 1$ and $\mathrm{P} 2$, respectively), muscle depth (20.8 and $19.54 \mathrm{~mm}$ in $\mathrm{P} 1$ and $\mathrm{P} 2$, respectively) and muscle eye area (8.93 and $8.71 \mathrm{~cm} 2$ in $\mathrm{P} 1$ and $\mathrm{P} 2$, respectively). The LD muscle depth measured in two points was similar with that reported by Ibrahim et al. (2007) for Kivircik lambs (19.6 mm). Dewi et al. (2002) used ultrasound measurements on Welsh Mountain lambs and found $3.5 \mathrm{~mm}$ fat layer thickness, 37\% higher than in TBH lambs, and $23.2 \mathrm{~mm}$ LD muscle depth, $12.9 \%$ higher than in TBH lambs. In comparison with 2-month-old Suffolk lambs taken as selection criteria for sheep meat with $30 \mathrm{~mm}$ LD muscle depth, $1.5 \mathrm{~mm}$ fat layer thickness and $10 \mathrm{~cm} 2$ muscle eye area, the values for TBH lambs were at medium level. Measuring the fat layer thickness at the same points, Silva et al. (2006) obtained values between 26.4-26.5 mm for muscle depth and 2.13$2.98 \mathrm{~mm}$ for fat layer thickness, while Orman et al. (2010) - $17.85 \mathrm{~mm}$ for muscle depth and $2.59 \mathrm{~mm}$ for the fat layer thickness. In our study, the muscle eye area in TBH lambs was similar to the values reported by Peña et al. (2005), but lower than the values given by Silva et al. (2006) and higher than values in studies of Ibrahim et al. (2007) and Orman et al. (2010). These results and the comparative analysis showed that TBH lambs had medium meat production performances. The ultrasound measurements on TBH lambs are similar with the average values of the standard for the meat breeds. The ultrasound measurements of subcutaneous fat layer thickness showed an average value of $2.03 \mathrm{~mm}$ in $\mathrm{P} 2,3.47 \%$ less than in P1 $(2.21 \mathrm{~mm})$. Muscle perimeter was $121.97 \mathrm{~mm}$ and $121.57 \mathrm{~mm}$ in $\mathrm{P} 1$ and $\mathrm{P} 2$, respectively. The results for the two measuring points were compared using one-factor ANOVA, and no significant difference was noticed.
Table 3. Commercial cuts weights, meat : bone ratio, bone percentage and slaughter and commercial yield in 2.5-month-old Teleorman Black Head lambs

\begin{tabular}{lrrrr}
\hline Indices & Mean & SEM & $\begin{array}{l}\text { Variability } \\
\text { coefficient, } \\
\%\end{array}$ & $\begin{array}{l}\text { Half } \\
\text { carcass, } \\
\%\end{array}$ \\
\hline $\begin{array}{l}\text { Cuts weight, kg } \\
\quad \text { leg }\end{array}$ & 1.67 & 0.06 & 13.24 & 33.30 \\
$\quad$ loin & 0.41 & 0.02 & 20.01 & 7.64 \\
$\quad$ rack & 0.68 & 0.03 & 15.80 & 13.43 \\
$\quad$ shoulder & 0.98 & 0.04 & 14.72 & 20.07 \\
$\quad$ flank & 0.90 & 0.06 & 23.78 & 18.17 \\
$\quad$ neck & 0.35 & 0.03 & 31.73 & 7.39 \\
$\quad$ half carcass & 4.99 & 0.22 & 15.54 & 100.00 \\
Meat : bone ratio & 2.07 & & & \\
Bone ratio, \% & 32.81 & & & \\
Slaughter yield, \% & 45.33 & & & \\
Commercial yield, \% & 51.66 & & & \\
\hline
\end{tabular}

Carcass measurements. The commercial and slaughter yields were $51.66 \%$ and $45.33 \%$, respectively (Table 3 ). The commercial cut with the highest percentage in half carcass was leg (33.3\%), followed by the shoulder $(20.07 \%)$ and flank $(18.17 \%)$, with similar values for the leg and shoulders to those reported by Peña et al. (2005) for Segurena lambs. The high quality commercial cuts in terms of muscle fibre structure and texture, the loin and rack, amounted $7.64 \%$ and $13.43 \%$ of the carcass, while in Peña et al. (2005) study $-7 \%$ and $17 \%$, respectively. In our study, these two parts together accounted $21.07 \%$ of the carcass weight, which shows that they are very well correlated with a large amount of quality meat. These two regions, loin and rack, are located entirely in the area of LD muscle which was analysed by ultrasound. The meat : bone ratio was 2.07 (Table 3). The largest proportion of meat determined after deboning 
Table 4. Meat and bone content in commercial cuts of Teleorman Black Head lambs carcass

\begin{tabular}{llllll}
\hline Cuts & & $\begin{array}{l}\text { Mean } \\
\text { weight, } \\
\mathrm{kg}\end{array}$ & SEM & $\begin{array}{l}\text { Variability } \\
\text { coefficient, } \\
\%\end{array}$ & $\begin{array}{l}\text { Percent } \\
\text { from cuts, } \\
\%\end{array}$ \\
\hline Leg & meat & 1.18 & 0.06 & 16.11 & 70.82 \\
& bone & 0.48 & 0.01 & 10.41 & 29.18 \\
Loin & meat & 0.26 & 0.02 & 22.92 & 61.88 \\
& bone & 0.16 & 0.01 & 17.92 & 38.12 \\
Rack & meat & 0.37 & 0.02 & 19.77 & 54.41 \\
& bone & 0.31 & 0.01 & 14.03 & 45.59 \\
Shoulder & meat & 0.70 & 0.04 & 17.62 & 71.54 \\
\multirow{2}{*}{ Flank } & bone & 0.28 & 0.01 & 8.39 & 28.46 \\
& meat & 0.63 & 0.05 & 28.37 & 69.83 \\
Neck & bone & 0.27 & 0.01 & 16.32 & 30.17 \\
& meat & 0.22 & 0.03 & 41.70 & 61.49 \\
Half & bone & 0.13 & 0.01 & 30.35 & 38.51 \\
carcass & beat & 3.37 & 0.19 & 19.42 & 67.48 \\
& & 1.62 & 0.04 & 9.19 & 32.52
\end{tabular}

was found in the shoulder $(71.54 \%)$ followed by the leg $(70.82 \%)$ (Table 4). In overall, meat content accounted $67.48 \%$ and bones $-32.5 \%$.

The commercial yield of TBH lambs was $6.34 \%$ higher than the slaughterhouse yield. These values were $2.68 \%$ lower than the slaughterhouse yield reported for Segurena lambs (Peña et al., 2005). In our study, the average carcass weight was $10.37 \mathrm{~kg}$. In a similar study, Peña et al. (2005) conducted studies on the influence of the body weight at slaughter on carcass quality on Segurena lambs, at the same age with the lambs slaughtered in our study, and reported $21.9 \mathrm{~kg}$ average weaning weight and $10.5 \mathrm{~kg}$ carcass weight. Cadavez and Monteiro (2011) reported $12.2 \mathrm{~kg}$ average carcass weight in Chura Bragancana lambs, while Orman et al. (2010) - $13.4 \mathrm{~kg}$ in Awassi lambs.

Correlations between the carcass measurements and the ultrasound measurements. Correlations have been calculated for the couples of traits obtained with the two methods, ultrasound (subcutaneous fat layer thickness, muscle depth, muscle eye area and LD muscle perimeter) and the body measurements (body weight at birth and at 2.5 months) (Table 5). The very close correlations were stated between body weight at birth and the subcutaneous fat layer thickness, muscle depth and muscle eye area in P1 (0.83, 0.84 and 0.81 , respectively). Very close correlations have also been determined in $\mathrm{P} 1$ between the weight at the age of 2.5 months and subcutaneous fat layer thickness, muscle depth and muscle eye area $(0.72,0.71$, and 0.82 ,
Table 5. Correlations between body weight measurements (at birth and at 2.5 month) and ultrasound carcass measurements performed in 2.5-month-old Teleorman Black Head lambs

\begin{tabular}{lll}
\hline Indices & BWB & BW2.5M \\
\hline BWB & 1.00 & \\
BW2.5M & $0.81^{* *}$ & 1.00 \\
FP1 & $0.83^{* *}$ & $0.72^{* *}$ \\
FP2 & $0.39^{* *}$ & $0.61^{* *}$ \\
MP1 & $0.84^{* *}$ & $0.71^{* *}$ \\
MP2 & $0.42^{* *}$ & $0.43^{* *}$ \\
AP1 & $0.81^{* *}$ & $0.82^{* *}$ \\
AP2 & $0.56^{* *}$ & $0.77^{* *}$ \\
PP1 & $0.61^{* *}$ & $0.80^{* *}$ \\
PP2 & $0.36^{* *}$ & $0.58^{* *}$
\end{tabular}

BWB - body weight at birth; BW2.5M - body weight at 2.5 month; FP1 - subcutaneous fat layer thickness in point 1 located $5 \mathrm{~cm}$ from the spine, in line with the $12^{\text {th }}$ rib (P1); FP2 - subcutaneous fat layer thickness in point 2 located between $3^{\text {rd }}$ and $4^{\text {th }}$ lumbar (P2); MP1 - muscle depth in P1; MP2 - muscle depth in P2; AP1 - muscle eye area in $\mathrm{P} 1 ; \mathrm{AP} 2$ - muscle eye area in $\mathrm{P} 2$; $\mathrm{PP} 1$ - muscle perimeter in P1; PP2 - muscle perimeter in P2; ${ }^{*}$ - significant correlations at $P<0.05 ;{ }^{* *}-$ highly significant correlations at $P<0.01$

respectively). It can be noticed that higher correlations were noticed in TBH lambs than in other breeds (Awassi, Kivircik, Welsh Montain, Segurena, Chura Galega Bragancana), which proves again their high genetic potential to improve meat quantity and quality. Similar results have been reported in Kivircik lambs by Ibrahim et al. (2007), who found strong correlations between body weight at birth and muscle depth (0.609) and muscle eye area (0.649). The same authors also reported strong correlations between the muscle eye area and muscle depth (0.845). In TBH lambs correlations were stronger than in other sheep breeds, which shows once more that they have a good genetic potential to improve quantity and quality of the meat produced by this local sheep.

The correlations between classical carcass measurements (meat amount for carcass and commercial cuts) and ultrasound measurements were also calculated (Table 6). Strong correlations have been determined between body weight, subcutaneous fat layer thickness and muscle depth in P1 (0.78, higher than those reported by Ripoll et al. (2010) and by Orman et al. (2010) for Chura Tensina $(0.65,0.68)$ and Awassi sheep (0.66, 0.48), respectively. Moderate correlations have been determined for these traits in TBH lambs in P2 $(0.57,0.43)$, slightly lower than those reported by Ripoll et al. (2010) $(0.58,0.63)$ in Chura Tensina lambs. In this study very strong correlations have been determined also between carcass weight and muscle eye area in P1 (0.88) and P2 (0.83), stronger than those 
Table 6. Correlations between classical carcass measurements (carcass and commercial cuts weights) and ultrasound measurements of 2.5-month-old Teleorman Black Head lambs

\begin{tabular}{|c|c|c|c|c|c|c|c|c|c|c|c|c|c|c|c|c|}
\hline Indices & Carcass & Leg & Loin & Rack & Shoulder & Flank & Neck & P leg & FP1 & FP2 & MP1 & MP2 & AP1 & AP2 & PP1 & PP2 \\
\hline Carcass & 1.00 & & & & & & & & & & & & & & & \\
\hline Leg & $0.97^{* *}$ & 1.00 & & & & & & & & & & & & & & \\
\hline Loin & $0.82^{* *}$ & $0.80^{* *}$ & 1.00 & & & & & & & & & & & & & \\
\hline Rack & $0.64^{* *}$ & $0.60^{* *}$ & $0.64^{* *}$ & 1.00 & & & & & & & & & & & & \\
\hline Shoulder & $0.93^{* *}$ & $0.92^{* *}$ & $0.67^{* *}$ & $0.38^{* *}$ & 1.00 & & & & & & & & & & & \\
\hline Flank & $0.92^{* *}$ & $0.86^{* *}$ & $0.66^{* \star}$ & $0.49^{* *}$ & $0.85^{\star *}$ & 1.00 & & & & & & & & & & \\
\hline Neck & $0.84^{* *}$ & $0.76^{* *}$ & $0.63^{* *}$ & $0.38^{* *}$ & $0.86^{* *}$ & $0.74^{* *}$ & 1.00 & & & & & & & & & \\
\hline Pleg & $0.64^{* *}$ & $0.54^{* *}$ & $0.56^{\star *}$ & $0.34^{* *}$ & $0.69^{* *}$ & $0.51^{* *}$ & $0.79^{* *}$ & 1.00 & & & & & & & & \\
\hline FP1 & $0.78^{* *}$ & $0.78^{* *}$ & $0.71^{* *}$ & $0.70^{* *}$ & $0.67^{\star *}$ & $0.62^{* *}$ & $0.64^{* *}$ & $0.34^{* *}$ & 1.00 & & & & & & & \\
\hline FP2 & $0.57^{* *}$ & $0.57^{* *}$ & $0.43^{* *}$ & 0.01 & $0.62^{* *}$ & $0.65^{* *}$ & $0.43^{* *}$ & $0.34^{* *}$ & 0.23 & 1.00 & & & & & & \\
\hline MP1 & $0.75^{* *}$ & $0.76^{* *}$ & $0.50^{* *}$ & $0.41^{* *}$ & $0.72^{\star *}$ & $0.70^{* *}$ & $0.70^{* *}$ & $0.29^{* *}$ & $0.69^{* *}$ & $0.51^{* *}$ & 1.00 & & & & & \\
\hline MP2 & $0.43^{* *}$ & $0.37^{* *}$ & $0.15^{*}$ & $0.42^{* *}$ & $0.42^{* *}$ & $0.46^{* *}$ & $0.32^{* *}$ & $0.26^{* *}$ & $0.51^{* *}$ & $0.28^{* *}$ & 0.13 & 1.00 & & & & \\
\hline AP1 & $0.88^{* *}$ & $0.90^{* *}$ & $0.59^{* *}$ & $0.39^{* *}$ & $0.91^{* *}$ & $0.79^{* *}$ & $0.82^{* *}$ & $0.44^{* *}$ & $0.77^{\star *}$ & $0.53^{* *}$ & $0.88^{* *}$ & $0.36^{* \star}$ & 1.00 & & & \\
\hline AP2 & $0.83^{* *}$ & $0.88^{* *}$ & $0.66^{* *}$ & $0.51^{* *}$ & $0.87^{* *}$ & $0.67^{* *}$ & $0.62^{* *}$ & $0.60^{* *}$ & $0.66^{* *}$ & $0.57^{* *}$ & $0.55^{\star *}$ & $0.50^{* *}$ & $0.77^{\star *}$ & 1.00 & & \\
\hline PP1 & $0.87^{\star *}$ & $0.85^{\star *}$ & $0.75^{\star *}$ & $0.41^{* *}$ & $0.87^{\star *}$ & $0.76^{* *}$ & $0.82^{* *}$ & $0.55^{\star \star}$ & $0.62^{* *}$ & $0.52^{\star *}$ & $0.76^{\star \star}$ & 0.15 & $0.88^{* *}$ & $0.71^{* *}$ & 1.00 & \\
\hline PP2 & $0.64^{* *}$ & $0.73^{* *}$ & $0.55^{\star *}$ & $0.25^{\star *}$ & $0.72^{* *}$ & $0.54^{* *}$ & $0.40^{* *}$ & $0.48^{* *}$ & $0.31^{* *}$ & $0.53^{\star *}$ & $0.47^{* *}$ & -0.01 & $0.58^{* *}$ & $0.81^{* *}$ & 0.62 & 1.00 \\
\hline
\end{tabular}

FP1 - subcutaneous fat layer thickness in point 1 located $5 \mathrm{~cm}$ from the spine, in line with the $12^{\text {th }}$ rib (P1); FP2 - subcutaneous fat layer thickness in point 2 located between $3^{\text {rd }}$ and $4^{\text {th }}$ lumbar (P2); MP1 - muscle depth in P1; MP2 - muscle depth in P2; AP1 - muscle eye area in P1; AP2 - muscle eye area in P2; PP1 - muscle perimeter in P1; PP2 - muscle perimeter in P2; P leg - leg perimeter; ${ }^{*}$ - significant correlations at $P<0.05 ;{ }^{* *}-$ highly significant correlations at $P<0.01$

reported by Orman et al. (2010) (0.76), and with LD muscle perimeter in P2 (0.87). Very close correlations were observed between carcass weight and muscle eye area in P1 and P2 (0.88 and 0.83, respectively), as well as with LD muscle perimeter in P1 (0.87). As it is known, the leg cut is very well correlated with a large amount of carcass meat, especially closely correlated with the carcass weight (0.97), but also with muscle eye area (0.90 and 0.88 for P1 and P2, respectively) and with LD muscle perimeter ( 0.85 and 0.73 for $\mathrm{P} 1$ and $\mathrm{P} 2$, respectively) (Table 6).

Non-linear multiple regression equations to estimate the amount of meat. Non-linear multiple regression equations have been formulated to estimate carcass meat content and meat content in commercial cuts with the use of ultrasound measurements (subcutaneous fat layer thickness, muscle depth, muscle eye area and LD muscle perimeter) and classical carcass measurements (body weight at birth and at 2.5 months). Two of these cuts - loin and rack, are located entirely between measurements points on this muscle and are very well correlated with a large amount of carcass meat (Peña et al., 2005).

In the present study equations have been developed using 4, 3 or 1 ultrasound parameter. The non-linear multiple regression equations with four parameters have been used to estimate the amount of meat at the two measurement points with a pre- cision of 0.902 in $\mathrm{P} 2$ and 0.839 in $\mathrm{P} 1$, much better than the results given by Orman et al. (2010), i.e. 0.68 . The subcutaneous fat layer thickness in P2 is closer to the leg cut, which is much better covered in muscles, and this fact may influence the negative value of the regression coefficient for the subcutaneous fat layer thickness at this measurement point. For each commercial cuts, leg, loin, rack, shoulder, flank and neck, the second measurement point, $\mathrm{P} 2$, has a negative regression coefficient, and if the commercial cut is larger, the regression coefficient is negative for the subcutaneous fat layer thickness.

The use of ultrasound measurements in P1 and carcass measurements in non-linear multiple regression equations gave the best estimations of meat in the carcass and in commercial cuts: 0.994 for the leg and loin, followed by 0.963 for the shoulder and 0.938 for the rack. The amount of meat in the flank (0.843) was estimated by ultrasound measurements in P2. The best estimations of the meat carcass using ultrasound measurements were in P2, while for the commercial cuts - in P1 (Table 7).

The use of three ultrasound parameters gave the best estimations of the carcass meat measured in P1 $(0.818)$, followed by the half carcass meat $(0.803)$. When only three out of the four (muscle depth, muscle eye area and LD muscle perimeter) ultrasound measurements were used, the best estimations for meat quantity were calculated in P1 (Table 8). 

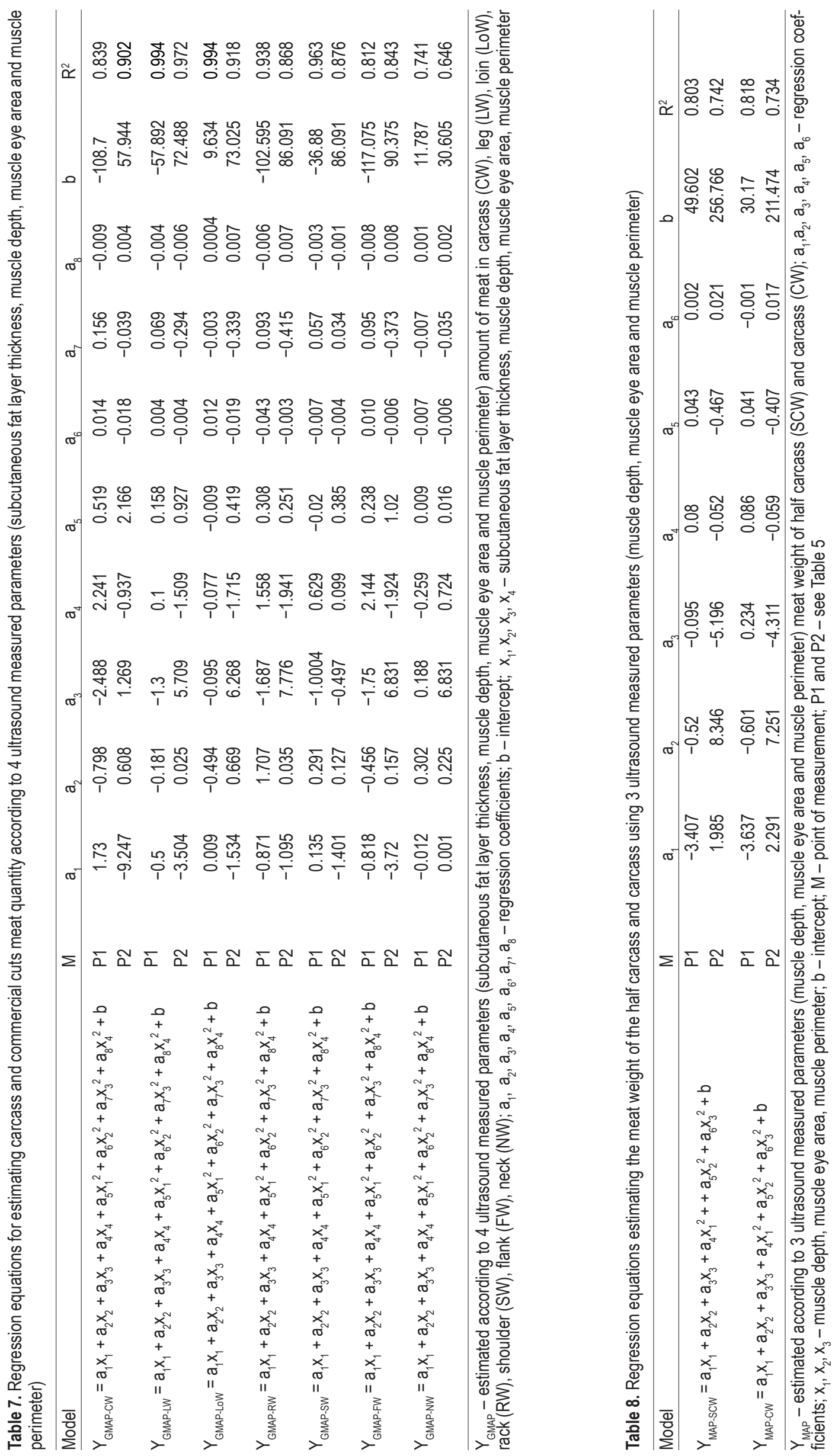


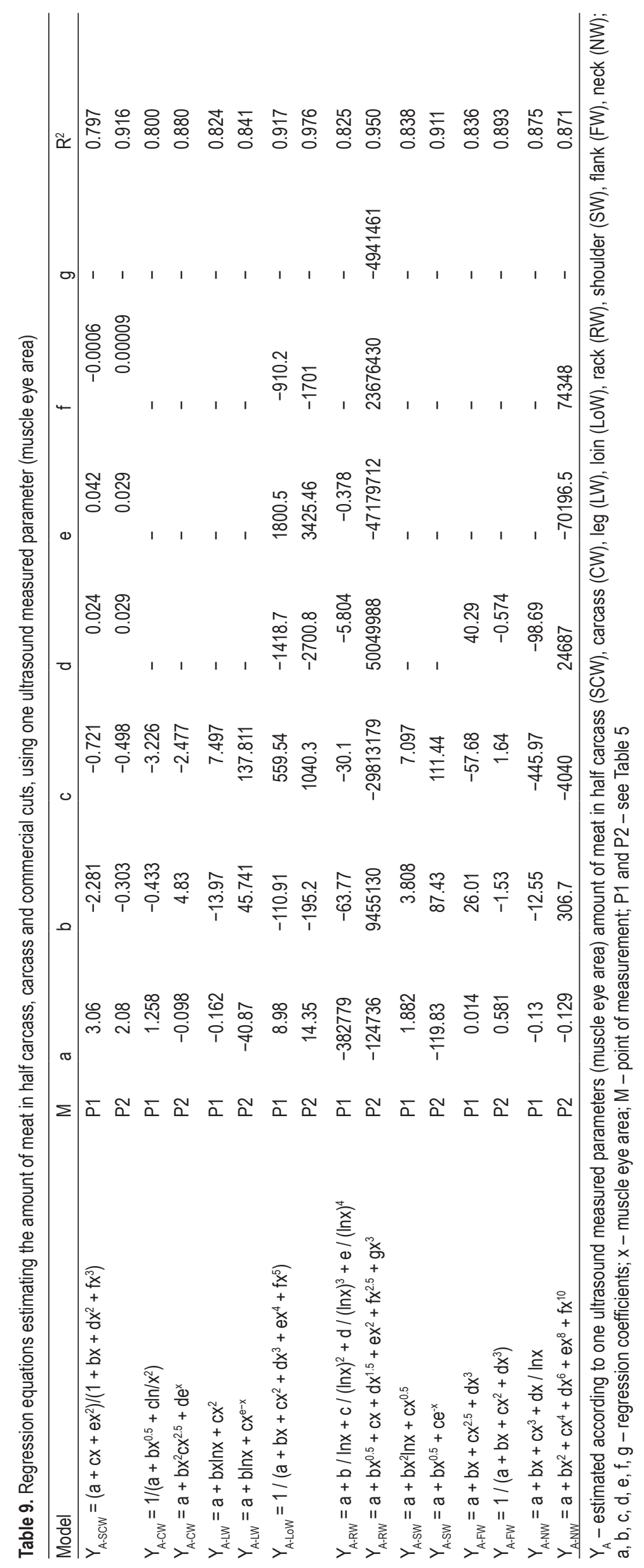


When just one ultrasound parameter was used as variable (muscle eye area) in non-linear multiple regression equations, the best estimations were obtained in P2 for the amount of meat in the half carcass (0.916) and carcass (0.880). Very high precisions for the amount of loin meat (0.976) were obtained using the ultrasound measurements in P2, followed by the amount of rack meat (0.950) and shoulder meat (0.911). Each commercial cut has a specific amount of muscle, and this amount influences the regression coefficient (Table 9).

The estimation of the carcass meat has been influenced by the muscle eye area, and each equation was developed using the non-linear multiple regression with Quattro pro X5 software. Similar studies have been performed on goat kids (Abdel-Mageed and Ghanem, 2013), where LD muscle eye area was determined with simple regression equations, using body measurements as variables; their precision was lower than that obtained by us using non-linear multiple regression equations with 4 ultrasound parameters as variables. Agamy et al. (2015) using ultrasound measurements to measure the carcass components in three sheep breeds, Barki, Ossimi and Rahmani, obtained lower precisions from the equations ( 0.63 for Ossimi and 0.85 for Rahmani) than the precision in this study for the amount of carcass meat $(0.880)$, followed by the amount of loin meat (0.976), rack meat (0.950) and shoulder meat (0.911). Hosseini Vardanjani et al. (2014) used simple regression equations, with body weight as variable, to estimate the weight of the warm carcass, and obtained a precision of 0.57 .

\section{Conclusions}

The use of ultrasound measurements has shown that Teleorman Black Head sheep breed has a large potential for meat production, standing out with a high proportion of commercial cuts with high quality meat. This breed has better performance for meat production than other world widely recognized sheep breeds. The ultrasounds measurements shows that a one-point measurement is enough to estimate the meat production of the carcass using ultrasound measurements. The nonlinear multiple regression equations developed by using ultrasounds parameters showed very high precision coefficients, which suggests that only ultrasound measurements and non-linear regression equations might be used to estimate the meat production and to improve the evaluation of the sheep selected for meat production.

\section{Acknowledgement}

This study was supported by Project No. PN093 80403 granted by Romanian Ministry of Education and Scientific Research.

\section{References}

Abdel-Mageed I., Ghanem N., 2013. Predicting body weight and longissimus muscle area using body measurements in subtropical goat kids. Egypt. J. Sheep Goat Sci. 8, 95-100

Abdel-Moneim A.Y., 2009. Body and carcass characteristics of Ossimi, Barki and Rahmani ram lambs raised under intensive production system. Egypt. J. Sheep Goat Sci. 4, 1-16

Agamy R., Abdel-Moneim A.Y., Abd-Alla M.S., Abdel-Mageed I.I., Ashmawi G.M., 2015. Use of ultrasound measurements to predict carcass characteristics of Egyptian ram-lambs. Asian J. Anim. Vet. Adv. 10, 203-214, https://doi.org/10.3923/ajava.2015.203.214

Cadavez V.A.P., Monteiro F.C., 2011. Comparison of alternative models to predict lean meat percentage of lamb carcasses. Int. J. Biol. Biomol. Agric. Food Biotechnol. Eng. 5, 841-845

Devitt C.J.B., Wilton J.W., 2001. Genetic correlation estimates between ultrasound measurements on yearling bulls and carcass measurements on finished steers. J. Anim. Sci. 79, 2790-2797, https://doi.org/10.2527/2001.79112790x

Dewi I.A., Saatci M., Ulutas Z., 2002. Genetic parameters of weights, ultrasonic muscle and fat depths, maternal effects and reproductive traits in Welsh Mountain sheep. Anim. Sci. 74, 399-408, https://doi.org/10.1017/S1357729800052541

Emenheiser J.C., Greiner S.P., Lewis R.M., Notter D.R., 2010. Longitudinal changes in ultrasonic measurements of body composition during growth in Suffolk ram lambs and evaluation of alternative adjustment strategies for ultrasonic scan data. J. Anim. Sci. 88, 1341-1348, https://doi.org/10.2527/jas.2009-2378

Fernández C., Gallego L., Quintanilla A., 1997. Lamb fat thickness and longissimus muscle area measured by a computerized ultrasonic system. Small Rumin. Res. 26, 277-282, https:// doi.org/10.1016/S0921-4488 (97)00007-2

Fernández C., García A., Vergara H., Gallego L., 1998. Using ultrasound to determine fat thickness and longissimus dorsi area on Manchego lambs of different live weight. Small Rumin. Res. 27, 159-165, http://doi.org/10.1016/S0921-4488 (97)00034-5

Flamant J.-C., Boccard R., 1966. Estimation de la qualité de la carcasse des agneaux de boucherie. Ann. Zootech. 15, 89-113, http://dx.doi.org/10.1051/animres:19660106

Fogarty N.M., 1995. Genetic parameters for live weight, fat and muscle measurements, wool production and reproduction in sheep: A review. Anim. Breed. Abs. 63, 101-143

Fogarty N.M., Banks R.G., Gilmour A.R., Brash L.D., 1992. Enhancement of LAMBPLAN to incorporate maternal traits and the eye muscle measurements. Proc. Aust. Assoc. Anim. Breed. Genet. 10, 63-66

Ghita E., Lazar C., Pelmus R, Voicu I., 2010. Comparative research on the fattening aptitude of the growing lambs of local Romanian breeds. Biotechnol. Anim. Husb. 26, 13-20, https://doi. org/10.2298/BAH1002013G

Hăbeanu M., Hebean V., Lefter N.A., Ropotă M., Panait Al.M., 2010. Effect of dietary n-3 polyunsaturated fatty acids on longissimus dorsi and semitendinosus muscle in pigs. Sci. Pap. Anim. Sci. Ser. 53, 844-849 
Hebean V., Hăbeanu M., Ciucă N., Voicu D., 2009. Brewer`s starch corn as alternative feed ingredient to improve efficacy and meta quality of Large White pigs in growing-finishing period. Arch. Zootech. 12, 46-55

Hosseini Vardanjani S.M., Miraei Ashtiani S.R., Pakdel A., Moradi Shahrebabak H., 2014. Accuracy of real-time ultrasonography in assessing carcass traits in Torki-Ghashghaii sheep. J. Agric. Sci. Technol. 16, 791-800

Houghton P.L., Turlington L.M., 1992. Application of ultrasound for feeding and finishing animals: a review. J. Anim. Sci. 70, 930-941, https://doi.org/10.2527/1992.703930x

Ibrahim C., Orhan K., Tufan A., Ozdal G., Murat Y., Onur Y., 2007. Ultrasounds measurements of eye muscle properties and backfat thickness in Kivircik lams. J. Biol. Sci. 7, 89-94, https://doi. org/10.3923/jbs.2007.89.94

Larsgard A.G., Kolstad K., 2003. Selection for ultrasonic muscle depth; direct and correlated response in a Norwegian experimental sheep flock. Small Rumin. Res. 48, 23-29, https://doi. org/10.1016/S0921-4488 (02)00291-2

Lazar C., Pelmus R., Ghita E., 2009. Research on body development dynamic of Carabsh lambs in suckling period. Sci. Pap. Anim. Sci. Ser. 52, 311-316

Orman A., Caliskan G.U., Dikmen S., 2010. The assessment of carcass traits of Awassi lambs by real-time ultrasound at different body weights and sexes. J. Anim. Sci. 88, 3428-3438, https:// doi.org/10.2527/jas.2009-2431
Peña F., Cano T., Domenech V., Alcalde Ma.J., Martos J., García-Martinez A., Herrera M., Rodero E., 2005. Influence of sex, slaughter weight and carcass weight on "non-carcass" and carcass quality in Segurena lambs. Small Rumin. Res. 60, 247-254, https://doi.org/10.1016/j.smallrumres.2004.12.011

Ripoll G., Joy M., Sanz A., 2010. Estimation of carcass composition by ultrasound measurementsin 4 anatomical locations of 3 commercial categories of lamb. J. Anim. Sci. 88, 3409-3418, https://doi.org/10.2527/jas.2009-2632

Russel A.J.F., 1995. Ultrasonography and body composition in sheep, In: P.J. Goddard (Editor). Veterinary Ultrasonography. CAB International. Wallingford (UK), pp. 315-324

Silva S.R., Afonso J.J., Santos V.A., Monteiro A., Guedes C.M., Azevedo J.M.T., Dias-da-Silva A., 2006. In vivo estimation of sheep carcass composition using real-time ultrasound with two probes of 5 and $7.5 \mathrm{MHz}$ and image analysis. J. Anim. Sci. 84, 3433-3439, https://doi.org/10.2527/jas.2006-154

Wilson D.E., 1992. Application of ultrasound for genetic improvement. J. Anim. Sci. 70, 973-983, https://doi.org/10.2527/1992. $703973 x$ 